\title{
CAMA
}

Centre for Applied Macroeconomic Analysis

\section{Do Sovereign Wealth Funds Dampen the Negative Effects of Commodity Price Volatility?}

\section{CAMA Working Paper 11/2017 February 2017}

\section{Kamiar Mohaddes}

Faculty of Economics and Girton College, University of Cambridge, UK and Centre for Applied Macroeconomic Analysis, ANU, Australia

\section{Mehdi Raissi}

International Monetary Fund, Washington DC, USA

\begin{abstract}
This paper studies the impact of commodity terms of trade (CTOT) volatility on economic growth (and its sources) in a sample of 69 commodity-dependent countries, and assesses the role of Sovereign Wealth Funds (SWFs) and quality of institutions in their long-term growth performance. Using annual data over the period 1981-2014, we employ the Cross-Sectionally augmented Autoregressive Distributive Lag (CS-ARDL) methodology for estimation to account for cross-country heterogeneity, cross-sectional dependence, and feedback effects. We find that while CToT volatility exerts a negative impact on economic growth (operating through lower accumulation of physical capital and lower TFP), the average impact is dampened if a country has a SWF and better institutional quality (hence a more stable government expenditure).
\end{abstract}




\title{
Keywords
}

Economic growth, commodity prices, volatility, sovereign wealth funds.

\author{
JEL Classification
}

C23, E32, F43, O13, O40

Address for correspondence:

(E) cama.admin@anu.edu.au

ISSN 2206-0332

The Centre for Applied Macroeconomic Analysis in the Crawford School of Public Policy has been established to build strong links between professional macroeconomists. It provides a forum for quality macroeconomic research and discussion of policy issues between academia, government and the private sector.

The Crawford School of Public Policy is the Australian National University's public policy school, serving and influencing Australia, Asia and the Pacific through advanced policy research, graduate and executive education, and policy impact. 


\title{
Do Sovereign Wealth Funds Dampen the Negative Effects of Commodity Price Volatility?*
}

\author{
Kamiar Mohaddes ${ }^{\mathrm{a} \dagger}$ and Mehdi Raissi ${ }^{\mathrm{b}}$ \\ ${ }^{a}$ Faculty of Economics and Girton College, University of Cambridge, UK \\ and Centre for Applied Macroeconomic Analysis, ANU, Australia \\ b International Monetary Fund, Washington DC, USA
}

February 2, 2017

\begin{abstract}
This paper studies the impact of commodity terms of trade (CToT) volatility on economic growth (and its sources) in a sample of 69 commodity-dependent countries, and assesses the role of Sovereign Wealth Funds (SWFs) and quality of institutions in their long-term growth performance. Using annual data over the period 1981-2014, we employ the Cross-Sectionally augmented Autoregressive Distributive Lag (CS-ARDL) methodology for estimation to account for cross-country heterogeneity, cross-sectional dependence, and feedback effects. We find that while CToT volatility exerts a negative impact on economic growth (operating through lower accumulation of physical capital and lower TFP), the average impact is dampened if a country has a SWF and better institutional quality (hence a more stable government expenditure).
\end{abstract}

JEL Classifications: C23, E32, F43, O13, O40.

Keywords: Economic growth, commodity prices, volatility, sovereign wealth funds.

\footnotetext{
*Kamiar Mohaddes acknowledges financial support from the Economic Research Forum (ERF). The views expressed in this paper are those of the authors and do not necessarily represent those of the ERF, International Monetary Fund or IMF policy.

${ }^{\dagger}$ Corresponding author. Email address: km418@cam.ac.uk.
} 


\section{Introduction}

Commodity-dependent countries are a heterogenous mix of high-, middle-, and low-income countries that possess a large share of the world's natural resources (around 90 percent of crude oil reserves for example), and represent close to 20 percent of world GDP and global exports. Natural resource wealth has enabled some of these countries to accumulate substantial assets (placed in Sovereign Wealth Funds in a growing number of countries), and provided a buffer against commodity-price shocks in several cases. However, not all resourcerich countries have been able to leverage their assets to raise long-term economic growth due to a number of factors, including pro-cyclical fiscal policies (especially in the Middle East), underdeveloped public financial management frameworks, and fragile political systems. For instance, Frankel et al. (2013) show that quality of institutions can play an important role in making fiscal policy less pro-cyclical, hence making commodity wealth a blessing rather than a curse. Moreover, when governments rely heavily on revenues derived from commodities, they are subject to commodity price volatility, which if not managed properly, can result in higher GDP growth volatility and disappointing long-term economic performance. ${ }^{1}$

This paper studies the impact of commodity price volatility on long-term economic growth in a sample of 69 commodity-dependent countries over the period 1981-2014, and assesses the role of Sovereign Wealth Funds (SWFs) and quality of institutions in shaping the growth performance of these countries in the face of the extreme volatility in resource revenues that they have experienced over time. The constructed Commodity Terms of Trade (CToT) volatility measure is based on a monthly country-specific commodity-price index that depends on the composition of a particular country's commodity export- and import-baskets, and is therefore weakly exogenous. Moreover, International Monetary Fund (2015) argues that strong institutions and appropriate stabilization buffers can increase the chances of a successful public investment scale-up, while Bahal et al. (2015) show that higher government spending on infrastructure facilities (like roads, highways, and power) and/or health and education may have a complementary impact on private sector investment by raising the marginal productivity of private capital. We therefore also study the possible growth channels - i.e. total factor productivity (TFP) and physical capital accumulation - through which CToT volatility (and SWFs) affect long-term economic growth.

We employ the Cross-Sectionally augmented Autoregressive Distributive Lag (CS-ARDL) approach for estimation to account for joint endogeneity of explanatory variables, crosscountry heterogeneity, and cross-sectional dependence. Accounting for these factors is par-

\footnotetext{
${ }^{1}$ For instance, over the 1981-2014 period GDP growth volatility in the Gulf Cooperation Council region (Bahrain, Kuwait, Oman, Qatar, Saudi Arabia, and the United Arab Emirates) has been at least three times higher than that of Chile and Norway.
} 
ticularly important in our panel data analysis as the effect of commodity price volatility on growth varies across cross-section units and depends critically on country-specific factors (such as quality of institutions, level of economic and financial development, strength of public financial management frameworks, and type of stabilization buffers) as well as feedback effects from determinants of GDP growth. Moreover, controlling for observed characteristics specific to countries alone need not ensure error cross-section independence. Neglecting such dependencies can lead to biased estimates and spurious inference, particularly given the rapid increase in globalization and exposures to global shocks.

Our results indicate that, on average, a highly-volatile CToT harms economic growth of natural resource dependent countries in the long term. This is primarily due to price volatility, which has been intrinsic in commodity markets. Nonetheless, there are significant heterogeneities across countries - some economies have been able to grow strongly and sustainably through multiple commodity price cycles (e.g. Chile and Norway), while many have not. Trying to explain such a heterogeneity, our econometric results also show that having a SWF, on average, can mitigate such negative growth effects, especially in countries that enjoy higher-quality institutions (and hence less pro-cyclical fiscal policies). While we do not explicitly model the impact of fiscal pro-cyclicality, International Monetary Fund (2015) argues that countries with weak political institutions are more prone to wasteful spending and pro-cyclical policies. Examining the channels through which these effects operate, we find that CToT volatility is associated with lower accumulation of physical capital, lower TFP, and thereby weaker growth. We show that long-term stabilization savings and sound institutional frameworks are essential for dampening the negative effects of CToT volatility via less frequent "stop-go" cycles in public investment and by enhancing productivity.

We are certainly not the first ones to emphasize the importance of volatility for economic growth. Ramey and Ramey (1995) discuss the consequences of excess volatility for longrun growth. Blattman et al. (2007) investigate the impact of terms of trade volatility on the growth performance of 35 commodity-dependent countries between 1870 and 1939 . Aghion et al. (2009), using data on 83 countries over 1960-2000, show that higher levels of exchange rate volatility can stunt growth, especially in countries with relatively underdeveloped capital markets. Bleaney and Greenaway (2001) estimate a model for 14 subSaharan African countries over 1980-1995 and show that growth is negatively affected by terms of trade volatility, and investment by real exchange rate instability. van der Ploeg and Poelhekke $(2009,2010)$ find that the volatility of unanticipated GDP growth has a negative impact on economic growth, conditional on the country's level of financial development.

Most closely related to our paper is Cavalcanti et al. (2015), who investigate the effects of CToT volatility $\left(\sigma_{C T O T}\right)$ on long-run economic growth of both commodity exporters and 
importers. However, we rely on a higher frequency (and exogenously determined) measure of $\sigma_{C T o T}$, use a different estimation technique, and most importantly, have a different focus: namely the role of SWFs and quality of institutions in mitigating the negative growth effects of $\sigma_{C T o T}$. While we do not explicitly control for other determinants of real GDP growth, the country-specific intercepts, different short-run slope coefficients and error variances, as well as cross-sectional averages of all the variables (as proxies for unobserved common factors) in the CS-ARDL regressions capture the effects of such unobserved variables/factors.

The rest of the paper is organized as follows: Section 2 discusses the econometric model and methodology; Section 3 presents the main results; and Section 4 concludes.

\section{The Econometric Model and Methodology}

We begin with the following panel data model that can nest much of the existing work on the empirics of economic growth, from the "Barro cross-sectional regression" to the static and dynamic panel data techniques:

$$
\begin{aligned}
\Delta y_{i t} & =(\phi-1) y_{i t-1}+\boldsymbol{\beta}^{\prime} \mathbf{x}_{i t}+c_{y i}+\eta_{t}+\varepsilon_{i t}, \\
\text { for } i & =1,2, \ldots, N \text { and } t=1,2, \ldots, T
\end{aligned}
$$

where $\Delta y_{i t}$ is the growth rate of real GDP per capita in country $i$; and $y_{i t-1}$ is the logarithm of lagged real GDP per capita. $\mathbf{x}_{i t}$ is a vector of explanatory variables; $\eta_{t}$ is the time-specific effect; $c_{y i}$ is the country-specific effect; and $\varepsilon_{i t}$ is the error term. Within this framework, the steady state output growth is exogenously determined by technological progress, while the speed of adjustment toward the equilibrium is a function of the determinants of steady state level of output and some initial conditions. Equation (1) allows one to study the potential determinants of steady state level of output and test the conditional convergence hypothesis in which countries converge to parallel equilibrium growth paths.

Much of the empirical growth literature is based on estimations of equation (1) using a cross-sectional approach or fixed/random effects panel estimators. Cross-sectional regressions clearly suffer from endogeneity problems as by construction, the initial level of income, $y_{i t-1}$, is correlated with the error term, $\varepsilon_{i t}$. This endogeneity bias is larger when considering the simultaneous determination of virtually all growth determinants, and the correlation of unobserved country-specific factors (arising from global shocks) and the explanatory variables. Traditional static panel data estimators such as fixed and random effects are not consistent either, due to the inclusion of lagged dependent variables in regressions (e.g. the initial level of GDP per capita). Specifically, the fixed effects estimator is inconsistent 
because it usually eliminates $c_{y i}$ by a de-meaning transformation that induces a negative correlation between the transformed error and the lagged dependent variables of order $1 / T$, which in short panels remains substantial. The assumption of a lack of correlation between $c_{y i}$ and the explanatory variables required for random effects consistency is also violated as both $\Delta y_{i t}$ and $y_{i t-1}$ are functions of $c_{y i}$. These estimators (or their standard errors) will be biased if the errors show either heteroscedasticity or serial correlation.

We specify our growth regression dynamically and include lagged GDP per capita on the right hand side. Hence, the elimination of fixed effects from equation (1) in any standard OLS-based estimation procedure implies the violation of the orthogonality condition between the error term and explanatory variables. For this reason, we estimate this equation using the CS-ARDL approach. While a system GMM estimator can effectively deal with the endogeneity problem and country-specific fixed effects, it restricts all the slope coefficients to be identical across countries; assumes that the time effects are homogenous; and that the errors are cross-sectionally independent. If any of these conditions are not satisfied, the GMM method can produce inconsistent estimates of the average values of parameters; see Pesaran and Smith (1995) for more details. The time-specific heterogeneity is an underestimated but at the same time very important concern in dynamic panel data models. Country-specific time-effects can capture a number of unobservable characteristics in macroeconomic and financial applications such as (a) institutional arrangements, (b) the patterns of trade, and (c) political developments. The time-specific heterogeneity is induced by oil price shocks, the stance of global financial cycles, and/or other global common factors, which affect all countries but to different degrees. The CS-ARDL methodology explained below accounts for heterogenous time effects and deals with cross-sectional dependencies effectively.

\subsection{CS-ARDL Methodology}

When panels of data are available, there exist a number of alternative estimation methods that vary on the extent to which they account for parameter heterogeneity. At one extreme is the Mean Group (MG) approach in which separate equations are estimated for each country and the average of estimated coefficients across countries is examined. Pesaran and Smith (1995) show that the MG method produces consistent estimates of the average of the parameters when the time-series dimension of the data is sufficiently large. At the other extreme are the traditional estimators in which dynamics are simply pooled and treated as homogeneous. Prominent examples include fixed effects (FE), random effects (RE), and generalized methods of moments (GMM). In between the two extremes is the pooled mean group (PMG) estimator of Pesaran and Shin (1999) which is an intermediate case between the 
averaging and pooling methods of estimation, and involves aspects of both. It restricts the long-run coefficients to be homogenous over the cross-sections, but allows for heterogeneity in intercepts, short-run coefficients (including the speed of adjustment) and error variances. The PMG estimator also generates consistent estimates of the mean of short-run coefficients across countries by taking the simple average of individual country coefficients.

We use the Cross-Sectionally augmented Autoregressive Distributive Lag (CS-ARDL) methodology of Chudik and Pesaran (2015) and Chudik et al. (2016a) to estimate, and report the pooled long-run estimates based on the PMG estimator because it offers the best available choice in terms of consistency and efficiency in our sample. ${ }^{2}$ The CS-ARDL method avoids the need for pre-testing the order of integration given that they are valid whether the variables of interest are $I(0)$ or $I(1)$. It is also robust to omitted variables bias and simultaneous determination of growth regressors. The main requirements for the validity of this methodology are that, first, there exists a long-run relationship among the variables of interest and, second, the dynamic specification of the model is sufficiently augmented so that the regressors become weakly exogenous and the resulting residual is serially uncorrelated.

To explain the CS-ARDL estimator in detail, consider the following panel $A R D L(1, \ldots, 1)$ model with a multifactor error structure:

$$
\begin{gathered}
y_{i t}=c_{y i}+\phi_{i} y_{i, t-1}+\boldsymbol{\beta}_{0 i}^{\prime} \mathbf{x}_{i t}+\boldsymbol{\beta}_{1 i}^{\prime} \mathbf{x}_{i, t-1}+u_{i t}, \\
u_{i t}=\gamma_{i}^{\prime} \mathbf{f}_{t}+\varepsilon_{i t}, \\
\boldsymbol{\omega}_{i t}=\left(\begin{array}{c}
\mathbf{x}_{i t} \\
\mathbf{g}_{i t}
\end{array}\right)=\mathbf{c}_{\omega i}+\boldsymbol{\alpha}_{i} y_{i, t-1}+\Gamma_{i}^{\prime} \mathbf{f}_{t}+\mathbf{v}_{i t},
\end{gathered}
$$

where as before $i=1,2, \ldots, N, t=1,2, \ldots, T$, and $\mathbf{x}_{i t}$ is $k_{x} \times 1$ vector of regressors specific to cross-section unit $i$ at time $t ; c_{y i}$ and $\mathbf{c}_{\omega i}$ are individual fixed effects for unit $i, \mathbf{g}_{i t}$ is $k_{g} \times 1$ vector of covariates specific to unit $i$ (not observed in the panel data model), $k_{x}+k_{g}=k$, $\varepsilon_{i t}$ are the idiosyncratic errors, $\Gamma_{i}$ is an $m \times k$ matrix of factor loadings $(k \geq m)$, $\boldsymbol{\alpha}_{i}$ is a $k \times 1$ vector of unknown coefficients, and $\mathbf{v}_{i t}$ is assumed to follow a general linear covariance stationary process distributed independently of $\varepsilon_{i t}$, the idiosyncratic errors. $\mathbf{f}_{t}$ is an $m \times 1$ vector of unobserved common factors, which can be stationary or nonstationary; see Kapetanios et al. (2011). The source of error term dependencies across countries is captured by $\mathbf{f}_{t}$, whereas the impacts of these factors on each country are governed by the idiosyncratic loadings in $\Gamma_{i}$. The individual-specific errors, $\varepsilon_{i t}$, are distributed independently across $i$ and $t$; they are not correlated with the unobserved common factors or the regressors; and they have zero mean, variance greater than zero, and finite fourth moments. The unobserved

\footnotetext{
${ }^{2}$ See also Chudik et al. (2013) and Chudik et al. (2016b) for other applications of the CS-ARDL method.
} 
common factors, or the heterogenous time effects, may be captured/proxied by adding crosssectional averages of the observables to our regressions, see Pesaran (2006) and Chudik and Pesaran (2015). ${ }^{3}$

Assuming that $N$ is sufficiently large, Chudik and Pesaran (2015) show that the unobserved common factors, $\mathbf{f}_{t}$, can be proxied by de-trended cross-section averages of $\mathbf{z}_{i t}=$ $\left(y_{i t}, \mathbf{x}_{i t}^{\prime}, \mathbf{g}_{i t}^{\prime}\right)^{\prime}$ and their lags:

$$
\mathbf{f}_{t}=\mathbf{G}(L) \widetilde{\mathbf{z}}_{w t}+O_{p}\left(N^{-1 / 2}\right),
$$

where $\mathbf{G}(L)$ is a distributed lag function, $\widetilde{\mathbf{z}}_{w t}=\overline{\mathbf{z}}_{w t}-\overline{\mathbf{c}}_{z w}$ is a $k+1$ dimensional vector of de-trended cross-section averages, $\overline{\mathbf{z}}_{w t}=\left(\bar{y}_{w t}, \overline{\mathbf{x}}_{w t}^{\prime}, \overline{\mathbf{g}}_{w t}^{\prime}\right)^{\prime}=\sum_{i=1}^{N} w_{i} \mathbf{z}_{i t}$ is a $k+1$ dimensional vector of cross-section averages, and $\overline{\mathbf{c}}_{z w}=\sum_{i=1}^{N} w_{i}\left(\mathbf{I}_{k+1}-\mathbf{A}_{i}\right)^{-1} \mathbf{c}_{z i}$. The weights satisfy the following normalization condition: $\sum_{i=1}^{N} w_{i}=1$.

Substituting (5) into (2), we obtain

$$
y_{i t}=c_{y i}^{*}+\phi_{i} y_{i, t-1}+\boldsymbol{\beta}_{0 i}^{\prime} \mathbf{x}_{i t}+\boldsymbol{\beta}_{1 i}^{\prime} \mathbf{x}_{i, t-1}+\boldsymbol{\delta}_{i}^{\prime}(L) \overline{\mathbf{z}}_{w t}+\varepsilon_{i t}+O_{p}\left(N^{-1 / 2}\right),
$$

where

$$
\boldsymbol{\delta}_{i}(L)=\sum_{\ell=0}^{\infty} \boldsymbol{\delta}_{i \ell} L^{\ell}=\mathbf{G}^{\prime}(L) \boldsymbol{\gamma}_{i}
$$

and $c_{y i}^{*}=c_{y i}-\boldsymbol{\delta}_{i}^{\prime}(1) \overline{\mathbf{c}}_{z w}$.

Equation (2) can be estimated using the MG and PMG estimators, however, for the estimators to be valid, a sufficient number of lags of cross-section averages must be included in individual equations of the panel (as we truncate the infinite polynomial distributed lag function $\boldsymbol{\delta}_{i}(L)$ ), and the number of cross-section averages must be at least as large as the number of unobserved common factors. Moreover, as always $T$ must be large enough so that the model can be estimated for each cross-section unit.

The estimated MG vector is defined as $\boldsymbol{\theta}=E\left(\boldsymbol{\theta}_{i}\right)$,where the individual long-run or level coefficients are

$$
\boldsymbol{\theta}_{i}=\frac{\boldsymbol{\beta}_{0 i}+\boldsymbol{\beta}_{1 i}}{1-\phi_{i}}
$$

To obtain the PMG estimates, the individual long-run coefficients are restricted to be the

\footnotetext{
${ }^{3}$ Conditioning on observed variables (growth regressors) specific to countries alone need not ensure error cross-section independence that underlies much of the panel data literature. Neglecting such dependencies can lead to biased estimates and spurious inference, particularly given the rapid increase in world trade, international financial linkages, and exposures to common shocks.
} 
same across countries, namely:

$$
\boldsymbol{\theta}_{i}=\boldsymbol{\theta}, \quad i=1,2, \ldots, N
$$

The PMG estimator uses a maximum likelihood approach to estimate the model based on the Newton-Raphson algorithm.

\section{Empirical Results}

To empirically test the relationship between economic growth and commodity terms of trade (CToT) growth, $g_{C T o T}$, and volatility, $\sigma_{C T o T}$, we use annual data from 1980 to 2014 on: real GDP per capita, a CToT index based on the prices of 45 primary commodities, a dummy variable that takes the value of one if a country has a SWF, and a measure of institutional quality. To investigate the possible mechanisms through which CToT volatility can harm economic growth, we focus on: (i) TFP growth; and (ii) physical capital accumulation. We obtain the data on real GDP, capital stock, and TFP from the Penn World Table Version 9.0 database and the institutional quality data from the Political Risk Services Group databases.

As in Spatafora and Tytell (2009), we define a country-specific measure of the CToT index as:

$$
C T o T_{i \tau}=\prod_{j}\left(\frac{P_{j \tau}}{M U V_{\tau}}\right)^{X_{i j}} / \prod_{j}\left(\frac{P_{j \tau}}{M U V_{\tau}}\right)^{M_{i j}}
$$

where $M U V_{\tau}$ is a manufacturing unit value index used as deflator, $X_{i j}\left(M_{i j}\right)$ is the share of exports (imports) of commodity $j$ in country $i$ 's GDP, and $P_{j \tau}$ is the individual commodity price in month $\tau$. We construct this monthly index based on data (on the prices of 45 primary commodities) obtained from the International Monetary Fund International Financial Statistics databases. Note that by construction, the movements in the CToT index are due to changes in commodity prices as the export and import shares are taken to be constant over time (i.e. long-term averages). The CToT index (10) allows countries to be influenced by changes in commodity prices differently, depending on the composition of their export and import baskets. This is in contrast to the "standard" commodity price indices most commonly used in the literature, such as the "All Primary Commodities Index" in International Monetary Fund (2012), which attaches the same weight to each country in the regression analysis. Equation (10) is then used to construct two important variables. The first is an annual CToT growth series, $g_{C T o T, i t}$, which is calculated in two steps: (i) year-on-year growth rate of the monthly CToT index is taken, and (ii) the average over the year is calculated. The second is a measure of realized CToT volatility for year $t, \sigma_{C T o T, i t}$, 
which is constructed as the standard deviation of the year-on-year growth rates of $C T o T_{i \tau}$ during months $\tau=1, \ldots, 12$ in year $t$. Therefore, in contrast to most studies in the growth literature which employ time-invariant measures of volatility, we construct a time-varying measure of commodity price volatility, $\sigma_{C T o T, i t}$.

Table 1: List of the 69 Primary Commodity Exporters Included in the Sample

\begin{tabular}{|c|c|c|c|}
\hline Algeria $^{12}$ & Egypt & Madagascar $^{2}$ & Qatar $^{1}$ \\
\hline Angola $^{12}$ & Ethiopia $^{2}$ & Malawi $^{2}$ & Russia $^{1}$ \\
\hline Argentina & Gabon $^{1}$ & Mali $^{2}$ & Saudi Arabia ${ }^{1}$ \\
\hline Armenia & Gambia $^{2}$ & Moldova & Senegal $^{1}$ \\
\hline Australia $^{1}$ & Ghana $^{12}$ & Mongolia $^{1}$ & Sierra Leone \\
\hline Azerbaijan $^{12}$ & Guatemala & Mozambique & Sudan \\
\hline Bahrain $^{1}$ & Guinea $^{2}$ & Myanmar $^{2}$ & Syria $^{2}$ \\
\hline Bolivia $^{1}$ & Guinea-Bissau $^{2}$ & Namibia & Togo \\
\hline Botswana $^{1}$ & Honduras & New Zealand ${ }^{1}$ & Trinidad and Tobago ${ }^{1}$ \\
\hline Brunei Darussalam ${ }^{12}$ & Iceland & Nicaragua & Tanzania \\
\hline Burkina Faso & Indonesia $^{1}$ & Niger & Uganda $^{2}$ \\
\hline Cameroon & $\operatorname{Iran}^{1}$ & Nigeria $^{1}$ & United Arab Emirates ${ }^{12}$ \\
\hline Chile $^{1}$ & Iraq & Norway $^{1}$ & Uruguay \\
\hline Colombia & Jamaica & Oman $^{12}$ & Venezuela $^{1}$ \\
\hline Congo $^{2}$ & Kazakhstan $^{1}$ & Panama $^{1}$ & Yemen $^{2}$ \\
\hline Côte d'Ivoire & Kenya & Paraguay & Zambia $^{2}$ \\
\hline Cyprus & Kuwait $^{1}$ & Peru $^{1}$ & Zimbabwe \\
\hline Ecuador & & & \\
\hline
\end{tabular}

Notes: Countries are classified as commodity exporters if primary commodities constitute more than 50 percent of their exports. 1 indicates that the country has a Sovereign Wealth Fund (SWF). The 20 countries which could not be included in the TFP and Physical Capital accumulation regressions due to unavailability of data are denoted by ${ }^{2}$.

The CS-ARDL method requires a sufficient number of time periods for consistent estimation of country-specific coefficients. To ensure this, we include only countries in our sample for which we have at least 25 consecutive annual observations on real GDP and CToT. Furthermore, we only focus on countries that are commodity dependant - those for which the ratio of primary commodities to total exports exceeds 50\%. Subject to these requirements, we end up with 69 countries in our sample - listed in Table 1. To identify which of these countries have established SWFs, we use information from the Sovereign Wealth Fund Institute and end up with 29 countries with SWFs in our sample denoted by ${ }^{1}$ in Table 1.

Figure 1 plots a simple bivariate relationship between real GDP per capita growth and its volatility (measured by its standard deviation over the full sample, 1981-2014), and shows that there exists a negative relationship between the two variables. The observation that higher volatility in output dampens growth was in fact discussed extensively in the seminal paper of Ramey and Ramey (1995). Moreover, we note that in our sample of 69 commodity- 
dependant countries, there appears to be a positive association between CToT volatility and GDP growth volatility - which in turn has a negative effect on output growth.

\section{Figure 1: Scatter Plots of GDP Growth and Volatility of CToT against Volatility of GDP Growth, 1981-2014}
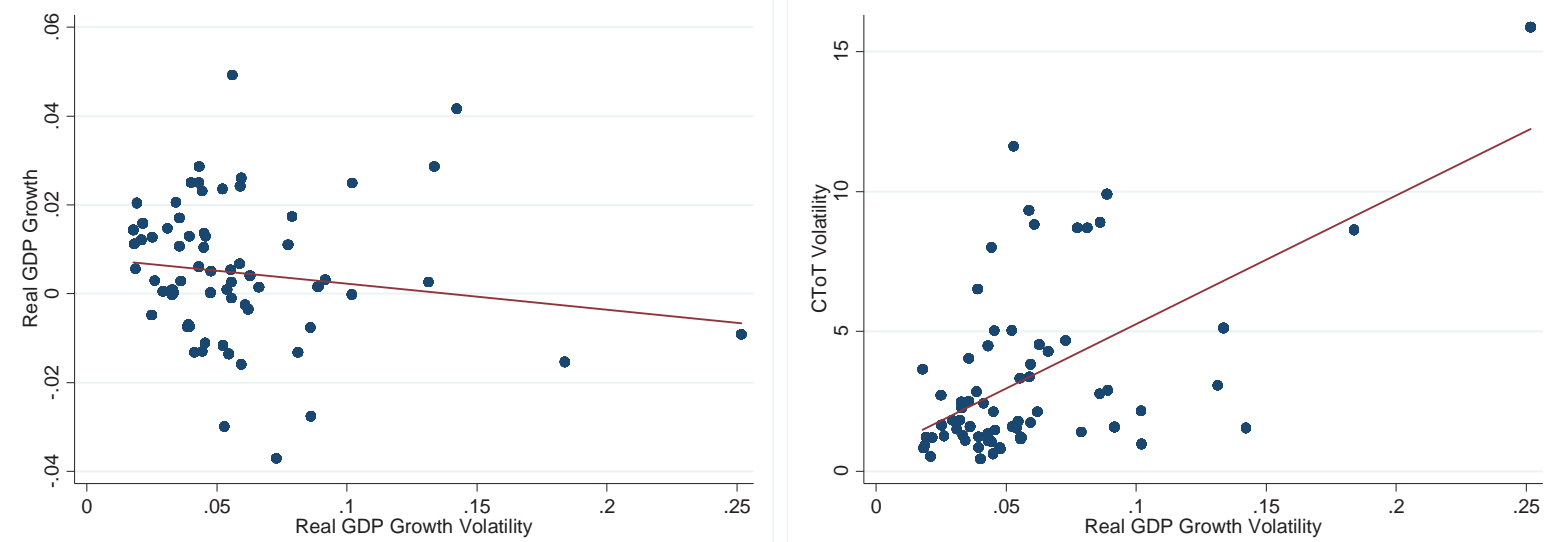

Source: Authors' calculation based on data from Penn World Table Version 9.0 and International Monetary Fund International Financial Statistics databases. These are cross-sectional averages over 1981-2014.

Figure 2 depicts a simple bivariate relationship between CToT volatility and the growth of real GDP per capita (as well as the growth rate of TFP and physical capital accumulation) in our sample of 69 countries over the period 1981-2014. They suggest that CToT volatility exerts a negative impact on economic growth operating mainly through lower productivity growth and lower physical capital accumulation. The rest of the paper use the CS-ARDL approach for estimation in order to investigate whether the above indicative results continue to hold up once we deal with, for instance, possible endogeneity problems, dynamics, crosscountry heterogeneity and cross-sectional dependence. We will also investigate the potential role of SWFs and institutions in dampening the negative effects of CToT volatility on growth.

\subsection{The Long-Run Effects of Volatility}

To examine the long-run effects of CToT volatility on output growth, we estimate the following panel CS-ARDL model:

$$
\Delta y_{i t}=c_{y i}^{*}+\sum_{l=1}^{p} \phi_{i l} \Delta y_{i, t-l}+\sum_{l=0}^{p} \boldsymbol{\beta}_{i l}^{\prime} \mathbf{x}_{i . t-l}+\sum_{l=0}^{q} a_{i l} \overline{\Delta y}_{t-l}+\sum_{l=0}^{q} \mathbf{b}_{i l}^{\prime} \overline{\mathbf{x}}_{t-l}+\varepsilon_{i t},
$$


Figure 2: Scatter Plots of CToT Volatility against Real GDP growth, TFP Growth and Capital Accumulation, 1981-2014
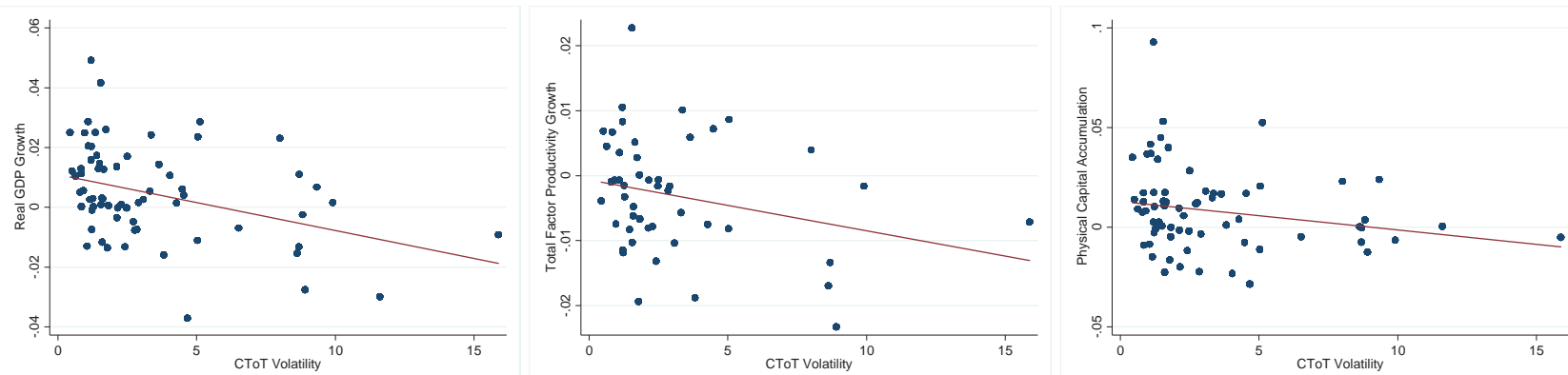

Source: Authors' calculation based on data from Penn World Table Version 9.0 and International Monetary Fund International Financial Statistics databases. These are cross-sectional averages over 1981-2014.

where $\Delta y_{i t}$ is the growth rate of real GDP per capita for country $i$ and year $t, \mathbf{x}_{i t}$ is a $2 \times 1$ vector of explanatory variables, namely the growth rate of the CToT index, $g_{C T o T, i t}$, and its volatility, $\sigma_{C T o T, i t}$. The terms $\overline{\Delta y}_{t}$ and $\overline{\mathbf{x}}_{t}$ denote the simple cross-section averages of $\Delta y_{i t}$ and $\mathbf{x}_{i t}$ in year $t$. Moreover, to determine the channel(s) through which GDP growth is negatively affected by CToT volatility in our sample, we follow Beck et al. (2000) in investigating two possible sources which are acknowledged in the literature, namely, TFP and physical capital investment. We therefore also estimate the following regressions:

$$
\Delta w_{i t}=c_{w i}^{*}+\sum_{l=1}^{p} \phi_{i l} \Delta w_{i, t-l}+\sum_{l=0}^{p} \boldsymbol{\beta}_{i l}^{\prime} \mathbf{x}_{i . t-l}+\sum_{l=0}^{q} a_{i l} \overline{\Delta w}_{t-l}+\sum_{l=0}^{q} \mathbf{b}_{i l}^{\prime} \overline{\mathbf{x}}_{t-l}+\varepsilon_{i t},
$$

where $\Delta w_{i t}=\ln W_{i t}-\ln W_{i t-1}$ is the growth rate of $W_{i t}=\{$ TFP or physical capital per capita for country $i$ and time $t\}$, while $\overline{\Delta w}_{t}$ is the simple cross-sectional average of $\Delta w_{i t}$, with all other variables as defined in equation (11). However, data on TFP and physical capital for some of the countries in our dataset were not available, and so these regressions are based on a sample of 49 countries (those which are not denoted by ${ }^{2}$ in Table 1 ).

While the order of the ARDL process must be chosen long enough to ensure that residuals of the error-correction model are serially uncorrelated, with a limited number of time-series observations, it should not be overextended as this imposes excessive parameter requirements on the data. Given the time-series requirements of the panel (with $T_{\min }=25$ and $T_{\max }=34$ ), we cap the lag order at three, in other words we set $p \leq 3$. In any case, given that we are working with growth rates which are only moderately persistent, a maximum lag order of 3 should be sufficient to fully account for the short-run dynamics. While, for completeness, 
we report the results for $p=1,2$, and 3 , we mainly rely on those with $p=3$.

Panel (a) in Table 2 reports the results of our baseline regressions in which the focus is on the growth impact of CToT volatility (as well as the channels of impact, discussed next). While the PMG estimate of the commodity terms of trade volatility is negative for all lag orders in the "Real GDP per capita" bloc, it is statistically significant at the $5 \%$ level only for $p=3$. Therefore, once we allow for long enough lags, to fully account for short-run dynamics, the results suggest that economic growth is adversely linked to commodity price volatility in the long-term. ${ }^{4}$ Moreover, $g_{C T o T}$, is significantly positively related to economic growth, but its impact on real GDP per capita is smaller than that of CToT volatility. Overall, while commodity price booms significantly increase economic growth, volatility affects it negatively. This finding can be partly explained by the fact that fiscal and current account balances of commodity-exporting countries are affected by swings in resources revenues with destabilizing effects on the macroeconomy. Note that the positive growth effect of $g_{C T o T}$ provides evidence against the traditional resource curse hypothesis, which argues that it is the level of resource abundance that affects economic growth negatively, and is in line with results obtained recently in the literature; see, for instance, Alexeev and Conrad (2009), Cavalcanti et al. (2011b, 2011a, 2015), El-Anshasy et al. (2015), and Esfahani et al. (2013).

We next turn to the long-run effects of CToT volatility on the two growth channels. The results, reported in the second and third blocs of panel (a) in Table 2, indicate that both commodity terms of trade growth and volatility have significant effects on TFP and physical capital accumulation for commodity abundant countries, with the coefficient of $\sigma_{C T o T, i t}$ being negative and significant across all lag orders. The negative association between CToT volatility and TFP growth lends itself to the argument that natural resource abundant countries have fewer possibilities for technological progress. Moreover, while a commodity price boom increases the physical capital stock, higher volatility of commodity prices significantly reduces it. Therefore, capital accumulation seems to be another important channel through which volatility affects GDP per capita growth; which is in line with what is argued in Gylfason and Zoega (2006) and Esfahani et al. (2014) among others.

A possible explanation for this finding is that economic agents tend to save less in commodity abundant countries because they perceive the revenues from primary commodity exports to be a permanent stream of future income. Another possibility is that the uncertainty arising from commodity price volatility might suppress the accumulation of physical capital by risk averse investors. Moreover, as noted by Catão et al. (2009), terms of trade volatility adversely affects capital accumulation and growth by raising the country's default

\footnotetext{
${ }^{4}$ See Mohaddes and Pesaran (2014) and Mohaddes and Pesaran (2016a) for the negative effects of oil revenue volatility on the Iranian economy.
} 
risk, hence widening the country spreads, and lowering its borrowing capacity.

Table 2: Estimates of the Long-Run Effects on Real GDP, TFP and Physical Capital Growth (1981-2014)

\begin{tabular}{|c|c|c|c|c|c|c|c|c|c|}
\hline \multirow{2}{*}{$\begin{array}{l}\text { Dependant variable } \\
\text { is the growth rate of: } \\
\text { Lags }\end{array}$} & \multicolumn{3}{|c|}{ Real GDP per capita } & \multicolumn{3}{|c|}{ Total Factor Productivity } & \multicolumn{3}{|c|}{ Physical Capital } \\
\hline & 1 & 2 & 3 & 1 & 2 & 3 & 1 & 2 & 3 \\
\hline \multicolumn{10}{|l|}{ (a) Baseline Regressions } \\
\hline CToT Growth & $\begin{array}{c}0.0015 \dagger \\
(0.0008)\end{array}$ & $\begin{array}{c}0.0028 \ddagger \\
(0.0009)\end{array}$ & $\begin{array}{c}0.0041 \ddagger \\
(0.0010)\end{array}$ & $\begin{array}{c}0.0023 \dagger \\
(0.0010)\end{array}$ & $\begin{array}{c}0.0033 \ddagger \\
(0.0011)\end{array}$ & $\begin{array}{c}0.0041 \ddagger \\
(0.0011)\end{array}$ & $\begin{array}{c}-0.0009 \\
(0.0007)\end{array}$ & $\begin{array}{c}0.0010 \\
(0.0009)\end{array}$ & $\begin{array}{c}0.0022 \dagger \\
(0.0010)\end{array}$ \\
\hline CToT Volatility & $\begin{array}{c}-0.0021 \\
(0.0017)\end{array}$ & $\begin{array}{c}-0.0020 \\
(0.0018)\end{array}$ & $\begin{array}{c}-0.0047 \dagger \\
(0.0021)\end{array}$ & $\begin{array}{c}-0.0054 \dagger \\
(0.0026)\end{array}$ & $\begin{array}{c}-0.0085 \ddagger \\
(0.0025)\end{array}$ & $\begin{array}{c}-0.0124 \ddagger \\
(0.0020)\end{array}$ & $\begin{array}{c}-0.0044 \dagger \\
(0.0022)\end{array}$ & $\begin{array}{r}-0.0045^{*} \\
(0.0026)\end{array}$ & $\begin{array}{r}-0.0079 \ddagger \\
(0.0028)\end{array}$ \\
\hline CD Test Statistic & -2.30 & -1.57 & -0.34 & -0.46 & 0.17 & 0.37 & -2.01 & -1.34 & -0.20 \\
\hline No Countries & 69 & 69 & 69 & 49 & 49 & 49 & 49 & 49 & 49 \\
\hline No Observations & 2,218 & 2,149 & 2,080 & 1,577 & 1,528 & 1,479 & 1,577 & 1,528 & 1,479 \\
\hline \multicolumn{10}{|c|}{ (b) Regressions with the Interactive Sovereign Wealth Fund (SWF) Dummy } \\
\hline CToT Growth & $\begin{array}{c}0.0015^{*} \\
(0.0008)\end{array}$ & $\begin{array}{c}0.0027 \ddagger \\
(0.0009)\end{array}$ & $\begin{array}{c}0.0038 \ddagger \\
(0.0010)\end{array}$ & $\begin{array}{c}0.0022 \dagger \\
(0.0010)\end{array}$ & $\begin{array}{c}0.0033 \ddagger \\
(0.0011)\end{array}$ & $\begin{array}{l}0.0041 \ddagger \\
(0.0011)\end{array}$ & $\begin{array}{c}-0.0009 \\
(0.0007)\end{array}$ & $\begin{array}{c}0.0011 \\
(0.0009)\end{array}$ & $\begin{array}{c}0.0023 \dagger \\
(0.0010)\end{array}$ \\
\hline CToT Volatility & $\begin{array}{c}-0.0039^{*} \\
(0.0023)\end{array}$ & $\begin{array}{c}-0.0043^{*} \\
(0.0024)\end{array}$ & $\begin{array}{c}-0.0067 \dagger \\
(0.0028)\end{array}$ & $\begin{array}{c}-0.0061^{*} \\
(0.0033)\end{array}$ & $\begin{array}{r}-0.0078 \dagger \\
(0.0032)\end{array}$ & $\begin{array}{c}-0.0113 \ddagger \\
(0.0025)\end{array}$ & $\begin{array}{r}-0.0057 \dagger \\
(0.0026)\end{array}$ & $\begin{array}{c}-0.0075 \dagger \\
(0.0031)\end{array}$ & $\begin{array}{r}-0.0117 \ddagger \\
(0.0036)\end{array}$ \\
\hline Interactive SWF Dummy & $\begin{array}{c}0.0041 \\
(0.0033)\end{array}$ & $\begin{array}{c}0.0064^{*} \\
(0.0034)\end{array}$ & $\begin{array}{c}0.0073^{*} \\
(0.0038)\end{array}$ & $\begin{array}{c}0.0022 \\
(0.0052)\end{array}$ & $\begin{array}{c}-0.0025 \\
(0.0051)\end{array}$ & $\begin{array}{l}-0.0047 \\
(0.0045)\end{array}$ & $\begin{array}{c}0.0060 \\
(0.0048)\end{array}$ & $\begin{array}{c}0.0112 \dagger \\
(0.0051)\end{array}$ & $\begin{array}{c}0.0110 \dagger \\
(0.0051)\end{array}$ \\
\hline CD Test Statistic & -2.38 & -1.68 & -0.37 & -0.46 & 0.14 & 0.33 & -2.06 & -1.38 & -0.22 \\
\hline No Countries & 69 & 69 & 69 & 49 & 49 & 49 & 49 & 49 & 49 \\
\hline No Observations & 2,218 & 2,149 & 2,080 & 1,577 & 1,528 & 1,479 & 1,577 & 1,528 & 1,479 \\
\hline
\end{tabular}

Notes: The CS-ARDL specifications are given by equations 11 and 12 . Symbols $\ddagger$, $\dagger$, and * denote significance at $1 \%$, $5 \%$, and $10 \%$ levels, respectively. CD is the cross-section dependence (CD) test of Pesaran $(2004,2015)$.

To determine the overall effect of changes in CToT growth and its volatility, we calculate the average percentage effect of the two CToT variables on output per capita and TFP growth rates as well as on the change in capital accumulation. We use the estimates based on $p=3$ in panel (a) of Table 2 and obtain an overall effect of between -0.01 and -0.03 percentage points per year, suggesting that the negative growth effects of CToT volatility offset the positive impact of commodity booms in the long run. We now need to ensure that we have successfully dealt with error cross-sectional dependence in our regressions. To this end, we report the cross-section dependence (CD) test of Pesaran (2004, 2015), which is based on the average of pair-wise correlations of the residuals from the underlying CS-ARDL regressions. Under the null of weak error cross-sectional dependence, the CD statistics are asymptotically distributed as $N(0,1)$, and therefore we cannot reject at the $10 \%$ level the null of no error cross sectional dependence for $p=2$ and 3 . 
Finally, as we expect the long-run growth effects of CToT volatility for primary commodity exporters to be different from those countries that are not dependant on a handful of primary products, we run the same regressions as in (11) but for a sample 61 countries that have a more diversified export basket. The results for these 61 countries show that CToT volatility is not significantly related to economic growth in the long-run. This is mainly because these countries have a more diversified basket of exports, especially manufacturing or service-sector goods, and so they are expected to grow faster and be better insured against price fluctuations in individual commodities. This is in contrast to the experience of the sample of 69 primary product exporters in Table 2, for which our results indicate that higher CToT volatility harms growth. The results for the sample of 61 diversified countries are not reported here, but are available upon request. ${ }^{5}$

\subsection{The Role of SWFs and Institutional Quality}

While many SWFs have been in existence for over half a century (such as the Kuwait Investment Authority which was founded in 1953), a large number of funds have been established (by major commodity exporters in particular) over the last two decades. These SWFs accumulated large assets during the most recent oil-price boom (2002-2008), have played a major role in reserve management of commodity revenues, and contributed to macroeconomic stabilization in several cases. SWFs have been established for a variety of reasons, ranging from fiscal stabilization (that is to help smooth the impact on government spending of revenues that are large and volatile), to long-term saving for future needs of the economy, or of specific groups such as pensioners, or for future generations. One of the main short-term objectives of SWFs is to counter the adverse macroeconomic effects of commodity price volatility. We next investigate whether SWFs have been successful, on average, in fulfilling this objective.

Using data from the Sovereign Wealth Fund Institute, we identify 29 countries in our sample as having established SWFs. These are denoted by ${ }^{1}$ in Table 1.19 of these are funded by revenue from exports of crude oil and gas, of which ten are members of the Organization of the Petroleum Exporting Countries (OPEC), and seven are located in the Persian Gulf. It is estimated by the Sovereign Wealth Fund Institute that in late 2016 the total assets of SWFs were around $\$ 7.5$ trillion with over $60 \%$ of these being funded by oil and gas exports. The prominent examples are Norway's Government Pension Fund (\$830), Abu Dhabi Investment Authority (\$773), Saudi Arabia's Fund (SAMA) (\$685), Kuwait Investment Authority (\$592), and Qatar Investment Authority (\$256), with the number in

\footnotetext{
${ }^{5}$ The asymmetric effects of CToT volatility on GDP growth in the two country groups considered (commodity dependant and more diversified countries) is also supported by the results in Cavalcanti et al. (2015).
} 
brackets referring to their market values in billions in June $2015 .^{6}$

To examine the role of SWFs in mitigating the negative growth effects of CToT volatility and the channels of impact, we add an interactive SWF dummy, $\left(S W F \times \sigma_{C T o T, i t}\right)$ where $S W F$ takes the value of unity if a country has established a SWF and zero otherwise, to the vector of explanatory variables, $\mathbf{x}_{i t}$, in equation (11). The results are reported in panel (b) of Table 2. As before, the long-run effects of $\sigma_{C T o T, i t}$ is negative for real GDP per capita growth and the channels of impact are lower TFP and physical capital accumulation. Note also that the coefficient of CToT volatility is negative and statistically significant for all lag orders. More importantly, the estimated coefficient of the interactive SWF dummy is positive and statistically significant in the first and third blocs. In other words, countries that have a SWF in our sample have, on average, performed better when it comes to mitigating the negative growth effects of CToT volatility and managed to sustain a higher level of capital accumulation in the face of the extreme volatility in resource revenues. Our results, therefore, suggests that one is better able to dampen the negative long-run growth effects of CToT volatility with a well-functioning SWF that can effectively deal with the adverse effects of (excess) commodity price volatility - add to the fund when commodity prices are high and transfer less to it or even withdraw from it when prices are low to smooth expenditure.

For instance, oil exporters in the Persian Gulf, enjoyed a large increase in their SWFs assets while oil prices were high for most of the past decade, but more recently many of them have dipped into their SWFs following the collapse in oil prices since 2014. ${ }^{7}$ Rather than cutting back on public expenditure (social welfare programs, public salaries, and infrastructure spending), many governments either withdrew money from their funds (such as Russia and Saudi Arabia) or alternatively transferred less revenue to these funds. To give a concrete example, since 1976 the Kuwaiti government has by law transferred a minimum of 10 percent of all state revenues to the Future Generation Fund (FGF). However, with oil prices having been high for almost a decade it was announced in March 2013, following an Amir budgetary decree, that the minimum contribution is to be increased to 25 percent. But the following year oil prices fell sharply and remained low, and so the decision was reversed and the contribution to the FGF was cut back to 10 percent from fiscal year 2015/16.

We next check the robustness of our results to the definition of SWF and re-estimate our growth regressions (11) excluding the seven countries whose SWFs are mainly funded by non-commodity revenues (Australia, Bolivia, Indonesia, New Zealand, Panama, Peru, and

\footnotetext{
${ }^{6}$ Note that given the objective of these funds, on average $65 \%$ of the SWF assets are held in public and private equities (61\% Norway; 72\% SAMA; 65\% Kuwait; 68\% Qatar; 62\% Abu Dhabi-figures based on 2014). See Mohaddes and Pesaran (2016b) for more details.

${ }^{7}$ See also Mohaddes and Raissi (2015) who quantify the global macroeconomic consequences of falling oil prices due to the oil revolution in the United States.
} 
Senegal). The results are reported in Table 3 and echo those in Table 2: while the coefficient on volatility is negative and statistically significant across all lag orders, the coefficient of the interactive dummy is always positive and significant.

Table 3: Estimates of the Long-Run Effects on Real GDP Growth when Considering Institutions and Different SWF Groupings, (1981-2014)

\begin{tabular}{|c|c|c|c|c|c|c|}
\hline \multirow[b]{2}{*}{ Lags } & \multicolumn{3}{|c|}{$\begin{array}{l}\text { Excluding Non-Commodity SWFs } \\
\text { Full sample (69 Countries) }\end{array}$} & \multicolumn{3}{|c|}{$\begin{array}{c}\text { Role of Institutions } \\
29 \text { Countries with SWF }\end{array}$} \\
\hline & 1 & 2 & 3 & 1 & 2 & 3 \\
\hline CToT Growth & $\begin{array}{l}0.0014^{*} \\
(0.0008)\end{array}$ & $\begin{array}{l}0.0025 \ddagger \\
(0.0009)\end{array}$ & $\begin{array}{l}0.0035 \ddagger \\
(0.0010)\end{array}$ & $\begin{array}{l}0.0025 \dagger \\
(0.0012)\end{array}$ & $\begin{array}{c}0.0020 \\
(0.0013)\end{array}$ & $\begin{array}{l}0.0026^{*} \\
(0.0014)\end{array}$ \\
\hline CToT Volatility & $\begin{array}{c}-0.0056 \dagger \\
(0.0023)\end{array}$ & $\begin{aligned}-0.0069 \ddagger \\
(0.0024)\end{aligned}$ & $\begin{array}{l}-0.0124 \ddagger \\
(0.0027)\end{array}$ & $\begin{array}{r}-0.0283^{*} \\
(0.0161)\end{array}$ & $\begin{array}{r}-0.0364 \dagger \\
(0.0169)\end{array}$ & $\begin{aligned}-0.0527 \ddagger \\
(0.0167)\end{aligned}$ \\
\hline Interactive SWF Dummy & $\begin{array}{l}0.0080 \dagger \\
(0.0033)\end{array}$ & $\begin{array}{l}0.0127 \ddagger \\
(0.0035)\end{array}$ & $\begin{array}{r}0.0167 \ddagger \\
(0.0038)\end{array}$ & - & - & - \\
\hline Interactive Institutional Term & - & - & - & $\begin{array}{l}0.0004^{*} \\
(0.0002)\end{array}$ & $\begin{array}{l}0.0005 \dagger \\
(0.0002)\end{array}$ & $\begin{aligned} 0.0007 \ddagger \\
(0.0002)\end{aligned}$ \\
\hline CD Test Statistic & -2.49 & -1.82 & -0.53 & 1.06 & 0.54 & -0.06 \\
\hline No Countries & 69 & 69 & 69 & 29 & 29 & 29 \\
\hline No Observations & 2,218 & 2,149 & 2,080 & 927 & 898 & 869 \\
\hline
\end{tabular}

Notes: The dependant variable is the growth of real GDP per capita. See also notes to Table 2.

Our results are in line with a number of recent papers that investigate the role of oil/stabilization funds in (i) reducing fiscal pro-cyclicality and (ii) smoothing government consumption. ${ }^{8}$ Coutinho et al. (2013) argue that resource funds tend to dampen fiscal pro-cyclicality. Sugawara (2014) shows that government expenditure volatility is lower in countries with stabilization funds. Koh (2016) illustrates that fiscal policy becomes more counter-cyclical after the establishment of oil funds, and that these funds are typically associated with smoother government consumption. Moreover, Shabsigh and Ilahi (2007) argue that oil funds help reduce macroeconomic volatility in oil exporting countries, more specifically, the volatility of broad money, prices, and (to some extent) the real exchange rate.

Given the large heterogeneity within the 29 SWF countries in our sample, a follow-up question is the potential role of institutions and policy frameworks, and in particular fiscal policy, in dampening the negative effect of CToT volatility. To investigate this issue, we add an interactive term, $\left(I \times \sigma_{C T o T, i t}\right)$, to the vector of explanatory variables, $\mathbf{x}_{i t}$, in equations

\footnotetext{
${ }^{8}$ Note that there is a large literature investigating whether fiscal policy is pro-cyclical in emerging and developing countries. See, for instance, Villafuerte and Lopez-Murphy (2010), Erbil (2011), and Céspedes and Velasco (2014), who focus on a sample of oil producing and commodity abundant countries and argue that overall fiscal policy has been pro-cyclical in these countries.
} 
(11). I is based on data from the Political Risk Services Group databases, measuring the average quality of institutions between 1984-2012, and takes a value between 0 and 100 .

The results are reported in the second block of Table 3, and perhaps not surprisingly, illustrate that within the SWF sample, countries with stronger institutions, have been better able to mitigate the negative growth effects of CToT volatility. Note that the coefficient of $\sigma_{C T O T, i t}$ is negative and significant for all lag orders, while the coefficient of the interactive institutional quality term is positive and statistically significant for $p=1,2$, and 3 . These results are in line with Frankel et al. (2013), who argue that the better institutions in developing countries are, the more likely they are to pursue less procyclical or more countercyclical fiscal policy, as well as Sugawara (2014) who shows that the two significant factors in reducing government expenditure volatility are stronger institutions and fiscal rules. Overall, our results suggest that while volatility represents a fundamental barrier to economic prosperity, the establishment of SWFs, as well as appropriate institutions, can help mitigating the negative effects. Therefore, creating a mechanism of short-term management of commodity price volatility through stabilization funds should be a priority for commodity dependant countries, complemented by well-functioning public financial management systems.

\section{Concluding Remarks}

This paper contributed to the literature by examining empirically the effects of commodity price booms and CToT volatility on GDP per capita growth and its sources. We created an annual panel dataset and used the CS-ARDL approach to account for endogeneity, crosscountry heterogeneity, and cross-sectional dependence which arise from unobserved common factors. The main finding was that while CToT growth enhances real output per capita, CToT volatility exerts a negative impact on economic growth operating through lower accumulation of physical capital and lower TFP. Our econometric results also showed that, on average, having a SWF can mitigate such negative growth effects, especially in countries that enjoy higher-quality institutions (and hence less pro-cyclical fiscal policies).

Our results have strong policy implications. The undesirable consequences of commodity price volatility can be avoided if resource-rich countries are able to improve the management of volatility in resource income by setting up forward-looking institutions such as Sovereign Wealth Funds, or adopting short-term mechanisms such as stabilization funds with the aim of saving when commodity prices are high and spending accumulated revenues when prices are low. The government can also intervene in the economy by increasing public capital expenditure when private investment is low, using proceeds from the stabilization fund. Alternatively the government can use these funds to increase the complementarities of phys- 
ical and human capital, such as improving the judicial system, property rights, and human capital. This would increase the returns on investment with positive effects on capital accumulation, TFP, and growth. Improving the functioning of financial markets is also a crucial step as this allows firms and households to insure against shocks, decreasing uncertainty and therefore mitigating the negative effects of volatility on investment and economic growth. 


\section{References}

Aghion, P., P. Bacchetta, R. Rancière, and K. Rogoff (2009). Exchange Rate Volatility and Productivity Growth: The Role of Financial Development. Journal of Monetary Economics 56(4), 494-513.

Alexeev, M. and R. Conrad (2009). The Elusive Curse of Oil. The Review of Economics and Statistics 91(3), 586-598.

Bahal, G., M. Raissi, and V. Tulin (2015). Crowding-Out or Crowding-In? Public and Private Investment in India . IMF Working Paper WP/15/264.

Beck, T., R. Levine, and N. Loayza (2000). Finance and the Sources of Growth. Journal of Financial Economics 58(1-2), 261-300.

Blattman, C., J. Hwang, and J. G. Williamson (2007). Winners and Losers in the Commodity Lottery: The Impact of Terms of Trade Growth and Volatility in the Periphery 1870-1939. Journal of Development Economics 82(1), 156-179.

Bleaney, M. and D. Greenaway (2001). The Impact of Terms of Trade and Real Exchange Rate Volatility on Investment and Growth in Sub-Saharan Africa. Journal of Development Economics 65(2), 491-500.

Catão, L. A. V., A. Fostel, and S. Kapur (2009). Persistent Gaps and Default Traps. Journal of Development Economics 89(2), 271-284.

Cavalcanti, T. V. d. V., K. Mohaddes, and M. Raissi (2011a). Growth, Development and Natural Resources: New Evidence Using a Heterogeneous Panel Analysis. The Quarterly Review of Economics and Finance 51(4), 305-318.

Cavalcanti, T. V. d. V., K. Mohaddes, and M. Raissi (2011b). Does Oil Abundance Harm Growth? Applied Economics Letters 18(12), 1181-1184.

Cavalcanti, T. V. D. V., K. Mohaddes, and M. Raissi (2015). Commodity Price Volatility and the Sources of Growth. Journal of Applied Econometrics 30(6), 857-873.

Chudik, A., K. Mohaddes, M. H. Pesaran, and M. Raissi (2013). Debt, Inflation and Growth: Robust Estimation of Long-Run Effects in Dynamic Panel Data Models. Federal Reserve Bank of Dallas, Globalization and Monetary Policy Institute Working Paper No. 162. 
Chudik, A., K. Mohaddes, M. H. Pesaran, and M. Raissi (2016a). Long-Run Effects in Large Heterogeneous Panel Data Models with Cross-Sectionally Correlated Errors. In R. C. Hill, G. Gonzalez-Rivera, and T.-H. Lee (Eds.), Advances in Econometrics (Volume 36): Essays in Honor of Aman Ullah, Chapter 4, pp. 85-135. Emerald Publishing.

Chudik, A., K. Mohaddes, M. H. Pesaran, and M. Raissi (2016b). Is There a Debt-threshold Effect on Output Growth? Review of Economics and Statistics, forthcoming.

Chudik, A. and M. H. Pesaran (2015). Common Correlated Effects Estimation of Heterogeneous Dynamic Panel Data Models with Weakly Exogenous Regressors. Journal of Econometrics 188(2), 393-c420.

Coutinho, L., D. Georgiou, M. Heracleous, A. Michaelides, and S. Tsani (2013). Limiting Fiscal Procyclicality: Evidence from Resource-Rich Countries. Centre for Economic Policy Research Working Paper DP9672.

Céspedes, L. F. and A. Velasco (2014). Was this Time Different?: Fiscal Policy in Commodity Republics. Journal of Development Economics 106, 92 - 106.

El-Anshasy, A., K. Mohaddes, and J. B. Nugent (2015). Oil, Volatility and Institutions: Cross-Country Evidence from Major Oil Producers. Cambridge Working Papers in Economics 1523.

Erbil, N. (2011). Is Fiscal Policy Procyclical in Developing Oil-Producing Countries? IMF Working Paper WP/11/171.

Esfahani, H. S., K. Mohaddes, and M. H. Pesaran (2013). Oil Exports and the Iranian Economy. The Quarterly Review of Economics and Finance 53(3), 221-237.

Esfahani, H. S., K. Mohaddes, and M. H. Pesaran (2014). An Empirical Growth Model for Major Oil Exporters. Journal of Applied Econometrics 29(1), 1-21.

Frankel, J. A., C. A. Vegh, and G. Vuletin (2013). On Graduation from Fiscal Procyclicality. Journal of Development Economics 100(1), 32 - 47.

Gylfason, T. and G. Zoega (2006). Natural Resources and Economic Growth: The Role of Investment. World Economy 29(8), 1091-1115.

International Monetary Fund, . (2012). International Financial Statistics, Washington DC. International Monetary Fund, . (2015). The Commodities Roller Coaster: A Fiscal Framework for Uncertain Times. Fiscal Monitor: October Edition. 
Kapetanios, G., M. H. Pesaran, and T. Yamagata (2011). Panels with Non-stationary Multifactor Error Structures. Journal of Econometrics 160(2), 326-348.

Koh, W. C. (2016). Fiscal Policy in Oil-exporting Countries: The Roles of Oil Funds and Institutional Quality. Review of Development Economics.

Mohaddes, K. and M. H. Pesaran (2014). One Hundred Years of Oil Income and the Iranian Economy: A Curse or a Blessing? In P. Alizadeh and H. Hakimian (Eds.), Iran and the Global Economy: Petro Populism, Islam and Economic Sanctions. Routledge, London.

Mohaddes, K. and M. H. Pesaran (2016a). Country-Specific Oil Supply Shocks and the Global Economy: A Counterfactual Analysis. Energy Economics 59, 382-399.

Mohaddes, K. and M. H. Pesaran (2016b). Oil Prices and the Global Economy: Is it Different this Time Around? USC-INET Research Paper No. 16-21.

Mohaddes, K. and M. Raissi (2015). The U.S. Oil Supply Revolution and the Global Economy. IMF Working Paper No. 15/259.

Pesaran, M. H. (2004). General Diagnostic Tests for Cross Section Dependence in Panels. IZA Discussion Paper No. 1240.

Pesaran, M. H. (2006). Estimation and Inference in Large Heterogeneous Panels with a Multifactor Error Structure. Econometrica 74(4), 967-1012.

Pesaran, M. H. (2015). Testing Weak Cross-Sectional Dependence in Large Panels. Econometric Reviews 34(6-10), 1089-1117.

Pesaran, M. H. and Y. Shin (1999). An Autoregressive Distributed Lag Modelling Approach to Cointegration Analysis. In S. Strom (Ed.), Econometrics and Economic Theory in 20th Century: The Ragnar Frisch Centennial Symposium, Chapter 11, pp. 371-413. Cambridge: Cambridge University Press.

Pesaran, M. H. and R. Smith (1995). Estimating Long-run Relationships from Dynamic Heterogeneous Panels. Journal of Econometrics 68(1), 79-113.

Ramey, G. and V. A. Ramey (1995). Cross-Country Evidence on the Link Between Volatility and Growth. The American Economic Review 85(5), 1138-1151.

Shabsigh, G. and N. Ilahi (2007). Looking Beyond the Fiscal: Do Oil Funds Bring Macroeconomic Stability? IMF Working Paper WP/07/96. 
Spatafora, N. and I. Tytell (2009). Commodity Terms of Trade: The History of Booms and Busts. IMF Working Paper No. 09/205.

Sugawara, N. (2014). From Volatility to Stability in Expenditure: Stabilization Funds in Resource-Rich Countries. IMF Working Paper WP/14/43.

van der Ploeg, F. and S. Poelhekke (2009). Volatility and the Natural Resource Curse. Oxford Economic Papers 61(4), 727-760.

van der Ploeg, F. and S. Poelhekke (2010). The Pungent Smell of "Red Herrings": Subsoil Assets, Rents, Volatility and the Resource Curse. Journal of Environmental Economics and Management 60(1), 44-55.

Villafuerte, M. and P. Lopez-Murphy (2010). Fiscal Policy in Oil Producing Countries During the Recent Oil Price Cycle. IMF Working Paper WP/10/28. 